\title{
Predictive Current Control Strategy With Imposed Load Current Spectrum
}

\author{
Patricio Cortés, Student Member, IEEE, José Rodríguez, Senior Member, IEEE, Daniel E. Quevedo, Member, IEEE,
} and Cesar Silva, Member, IEEE

\begin{abstract}
This paper presents a modified predictive current control strategy which allows one to have control over the spectrum of the load current. The proposed method uses a model of the system to predict the behavior of the current for each possible voltage vector generated by the inverter. For that purpose, at each sampling interval, signal predictions are evaluated using a cost function that quantifies the desired system behavior.

The cost function used in this work evaluates the filtered error of the load currents. The inclusion of a filter for the load error allows one to manipulate current spectra. Thus, by designing this filter appropriately, the load spectrum can be shaped. The performance of the proposed control strategy is verified by simulation and experimental results.
\end{abstract}

Index Terms-Current control, frequency control, frequency domain analysis, inverters, predictive control.

\section{INTRODUCTION}

G IVEN the powerful and fast microprocessors available today, increasing attention has been dedicated to the predictive control of power converters. In this method, load and converter models are used to predict current behavior. This allows one to select the most appropriate actuation following an arbitrary control criterion. Predictive control is a very wide concept and different control methods have been presented under this name. A classification of them is presented in [1].

The standard implementation of predictive current control [2] calculates the voltage required by the load to get the desired current. Then this voltage is applied using pulse width modulation (PWM). This scheme has been used for the control of single-phase [3] and three-phase inverters [4], [5], inverters with output LCL filter [6], rectifiers and active filters [2], [7], uninterruptible power supplies [8] and dc-dc converters [9]. This concept has also been used for torque control of induction machines, as shown in [22]. It is also possible to calculate the duty cycles for the converter instead of the voltages, as shown in [10].

Model predictive control (MPC) is a very powerful control strategy that uses the model of the system to precalculate the behavior of the system for a predefined horizon in the future. A

Manuscript received February 13, 2007; revised July 20, 2007. This paper was presented in part at the 12th International Power Electronics and Motion Control Conference (EPE-PEMC'06), Portoroz, Slovenia, 2006. This work was supported by the the Chilean Research Fund CONICYT under Grant 1050549, by the Industrial Electronics and Mechatronics Millennium Science Nucleus and by Universidad Técnica Federico Santa María. Recommended for publication by Associate Editor M. Ferdowski.

P. Cortés, J. Rodríguez, and C. Silva are with the Departamento de Electrónica, Universidad Técnica Federico Santa María, Valparaíso 110-V, Chile (e-mail: patricio.cortes@elo.utfsm.cl).

D. E. Quevedo is with the School of Electrical Engineering and Computer Science, The University of Newcastle, Newcastle NSW 2308, Australia

Digital Object Identifier 10.1109/TPEL.2007.915605 cost function evaluates the precalculated results and determines the optimal future control actions. This scheme has been applied in electrical drives in [11]-[13].

Another approach of predictive control is to consider the converter as a system with a finite number of possible states (and possible voltage vectors) and to select, for each sampling period, the voltage vector (or switching state) that minimizes a certain cost function. These cost functions define the desired behavior of the system, and may include different variables to be controlled. Some works have been presented using this scheme for current control in a three-phase inverter [14] and a matrix converter [15], flux and torque control of an induction machine [16] and direct power control in an active front end rectifier [17]. An example of different variables controlled using a single cost function is presented in [18], where the current is controlled while, at the same time, minimizing the switching frequency and balancing the dc-link voltages in a neutral point clamped inverter. In all these works the switching states are changed at equidistant time instants. Although the switching frequency is limited to half the sampling frequency, the load voltage spectrum is spread over a wide range of frequencies. This is not desirable in some situations.

The discrete nature of the power converters has been also studied in [19], where concepts of MPC are utilized to reduce the electromagnetic interference in a switch-mode power supply by spreading the spectrum to reduce the peaks in spectra of voltages and currents within the power supply.

In the present work, we will show how the concepts presented in [19], see also [20], can also be used to shape the spectrum in other ways. For that purpose we present a modified scheme which overcomes the problem of having a spread spectrum. By adding a filter to the variable that the cost function evaluates, i.e., by evaluating the filtered current error, it is possible to manipulate the spectrum of the load current by choosing an appropriate filter.

\section{SYSTEM MODEL}

The power circuit of the converter considered in this work is shown in Fig. 1.

The switching states of the converter are determined by the gating signals $S_{a}, S_{b}$ and $S_{c}$ as follows:

$$
\begin{aligned}
& S_{a}= \begin{cases}1, & \text { if } S_{1} \text { on and } S_{4} \text { off } \\
0, & \text { if } S_{1} \text { off and } S_{4} \text { on }\end{cases} \\
& S_{b}= \begin{cases}1, & \text { if } S_{2} \text { on and } S_{5} \text { off } \\
0, & \text { if } S_{2} \text { off and } S_{5} \text { on }\end{cases} \\
& S_{c}= \begin{cases}1, & \text { if } S_{3} \text { on and } S_{6} \text { off } \\
0, & \text { if } S_{3} \text { off and } S_{6} \text { on }\end{cases}
\end{aligned}
$$




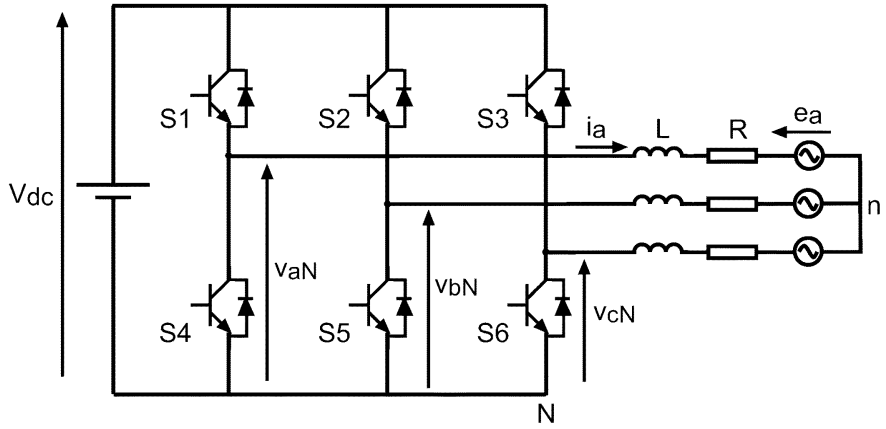

Fig. 1. Voltage source inverter power circuit.

and can be expressed in vectorial form by

$$
\mathbf{S}=\frac{2}{3}\left(S_{a}+\mathbf{a} S_{b}+\mathbf{a}^{2} S_{c}\right)
$$

where $\mathbf{a}=e^{j(2 \pi / 3)}$.

The output voltage space vectors generated by the inverter are defined by

$$
\mathbf{v}=\frac{2}{3}\left(v_{a N}+\mathbf{a} v_{b N}+\mathbf{a}^{2} v_{c N}\right)
$$

where $v_{a N}, v_{b N}$ and $v_{c N}$ are the phase to neutral $(N)$ voltages of the inverter (Fig. 1). The load voltage vector $\mathbf{v}$ can be related to the switching state vector $\mathbf{S}$ by

$$
\mathbf{v}=V_{d c} \mathbf{S}
$$

where $V_{d c}$ is the dc link voltage.

Considering all the possible combinations of the gating signals $S_{a}, S_{b}$ and $S_{c}$, eight switching states and consequently eight voltage vectors are obtained. Note that $\mathbf{v}_{0}=\mathbf{v}_{7}$, resulting in a finite set of only seven different voltage vectors.

Using modulation techniques, like PWM, the inverter can be approximated as a linear system. Nevertheless, in this paper the inverter is considered as a non-linear discrete system with only seven different states as possible outputs.

We note that a more accurate model of the converter model could be used for higher switching frequencies. It may include deadtime, IGBT saturation voltage and diode forward voltage drop, for example. Nevertheless, in this work, emphasis has been put in simplicity, so a simple model of the inverter will be used.

\section{A. Load Model}

In a balanced three-phase load the current can be defined as a space vector by

$$
\mathbf{i}=\frac{2}{3}\left(i_{a}+\mathbf{a} i_{b}+\mathbf{a}^{2} i_{c}\right)
$$

and the load EMF as

$$
\mathbf{e}=\frac{2}{3}\left(e_{a}+\mathbf{a} e_{b}+\mathbf{a}^{2} e_{c}\right) .
$$

In this way, the load current dynamics can be described by the vector differential equation

$$
\mathbf{v}=R \mathbf{i}+L \frac{d \mathbf{i}}{d t}+\mathbf{e}
$$

where $R$ is the load resistance, $L$ the load inductance, $\mathbf{v}$ the voltage generated by the inverter and e the load back-EMF.

For simulation and experimental results, the load back-EMF is assumed to be sinusoidal with constant amplitude and constant frequency.

\section{B. Discrete-Time Model}

A discrete-time form of the load current (9) for a sampling time $T_{s}$ can be used to predict the future value of load current from voltages and measured currents at the $k$ th sampling instant.

Approximating the derivative $d \mathbf{i} / d t$ by

$$
\frac{d \mathbf{i}}{d t} \approx \frac{\mathbf{i}(k+1)-\mathbf{i}(k)}{T_{s}}
$$

and replacing it in (9), the following expression is obtained for the future load current:

$$
\hat{\mathbf{i}}(k+1)=\left(1-\frac{R T_{s}}{L}\right) \mathbf{i}(k)+\frac{T_{s}}{L}(\mathbf{v}(k)-\hat{\mathbf{e}}(k))
$$

where the term $R T_{s} / L$ could be neglected if the sampling period is small enough and the load is mainly inductive.

To take into account the unitary implementation delay of any control law within this context, at time $k$, one calculates $\mathbf{v}(k+$ 1). Accordingly, the dynamic model (11) needs to be iterated to give

$$
\begin{aligned}
\hat{\mathbf{i}}(k+2)=\left(1-\frac{R T_{s}}{L}\right) \hat{\mathbf{i}}( & k+1) \\
& +\frac{T_{s}}{L}(\mathbf{v}(k+1)-\hat{\mathbf{e}}(k+1)) .
\end{aligned}
$$

In (12), $\hat{\mathbf{i}}(k+1)$ is an estimate of the load current, which is obtained from (11) given the measurement $\mathbf{i}(k)$ and the previous control $\mathbf{v}(k) ; \hat{\mathbf{e}}(k+1)$ denotes the estimated back-EMF. It can be calculated using (9) and measurements of the load voltage and current, resulting in the following expression:

$$
\hat{\mathbf{e}}(k-1)=\mathbf{v}(k-1)-\frac{R T_{s}+L}{T_{s}} \mathbf{i}(k)+\frac{L}{T_{s}} \mathbf{i}(k-1)
$$

where $\hat{\mathbf{e}}(k-1)$ is the estimated value of $\mathbf{e}(k-1)$. The present back-EMF, needed in (11), can be estimated using an extrapolation of the past values of the estimated back-EMF. Alternatively, as the frequency of the back-EMF is much smaller than the sampling frequency, in the sequel we will suppose that it does not change considerably in one sampling interval and, thus, assume $\hat{\mathbf{e}}(k)=\hat{\mathbf{e}}(k-1)$. For simplicity, in (12) we will also consider $\hat{\mathbf{e}}(k+1)=\hat{\mathbf{e}}(k-1)$.

Finally, in (12) the voltage $\mathbf{v}(k+1)$ denotes the decision variable to be calculated at time $k$. Details of our proposal are given in the following section. 


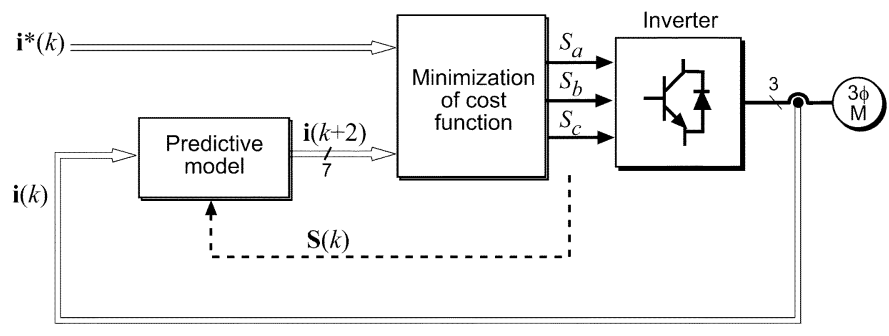

Fig. 2. Predictive current control block diagram.

\section{Proposed Predictive Control Strategy}

\section{A. Previous Control Strategies}

The purpose of the control strategy is to select, from the finite set of possible voltage vectors that the converter can generate, the one that minimizes the cost function $g$. Then the selected voltage vector is applied during the next sampling period.

In the scheme presented in [14], the cost function evaluates the predicted load current error, expressed in orthogonal coordinates, for the next sampling instant. This is obtained by defining the following cost function $g$ :

$$
g(k)=\left|i_{\alpha}^{*}(k)-\hat{i}_{\alpha}(k+2)\right|+\left|i_{\beta}^{*}(k)-\hat{i}_{\beta}(k+2)\right|
$$

where $\hat{i}_{\alpha}(k+2)$ and $\hat{i}_{\beta}(k+2)$ are the real and imaginary part of the predicted load current vector $\hat{\mathbf{i}}(k+2)$, for a given voltage vector. This prediction is obtained using (12). Currents $i_{\alpha}^{*}(k)$ and $i_{\beta}^{*}(k)$ are the real and imaginary part of the reference current vector $\mathbf{i}^{*}(k)$, which is obtained from an external control loop, for example a field oriented control of an induction machine. A block diagram of the control strategy is shown in Fig. 2.

By selecting the voltage vector to be applied taking into account the measured data from only one sampling instant, the resulting output voltage has not a regular pattern as the one obtained using PWM. Indeed, this way of obtaining the optimal voltage to be applied generates a spectrum that is spread over a wide range of frequencies, depending on the sampling frequency used for the control and the operating conditions. This is not desirable in some systems where a fixed switching frequency is preferred, e.g., for limiting the switching frequency and the switching losses, for filtering, and others. This disadvantage of the strategy described in [8] can be overcome by considering filtered signals in the cost function as described in the sequel.

\section{B. Frequency Weighted Predictive Control}

To achieve tight control of the load current spectrum we introduce the frequency weighted current error:

$$
\begin{aligned}
& i_{e \alpha}(k)=F(z)\left(i_{\alpha}^{*}(k)-\hat{i}_{\alpha}(k)\right) \\
& i_{e \beta}(k)=F(z)\left(i_{\beta}^{*}(k)-\hat{i}_{\beta}(k)\right)
\end{aligned}
$$

where $F$ is a discrete-time filter defined as

$$
F(z)=\frac{z^{0}+b_{1} z^{-1} \cdots b_{n} z^{-n}}{a_{0} z^{0}+a_{1} z^{-1} \cdots a_{n} z^{-n}}
$$

where $n$ is the order of the filter.

The associated cost function is given by

$$
h(k)=\left|i_{e \alpha}(k+2)\right|+\left|i_{e \beta}(k+2)\right| .
$$
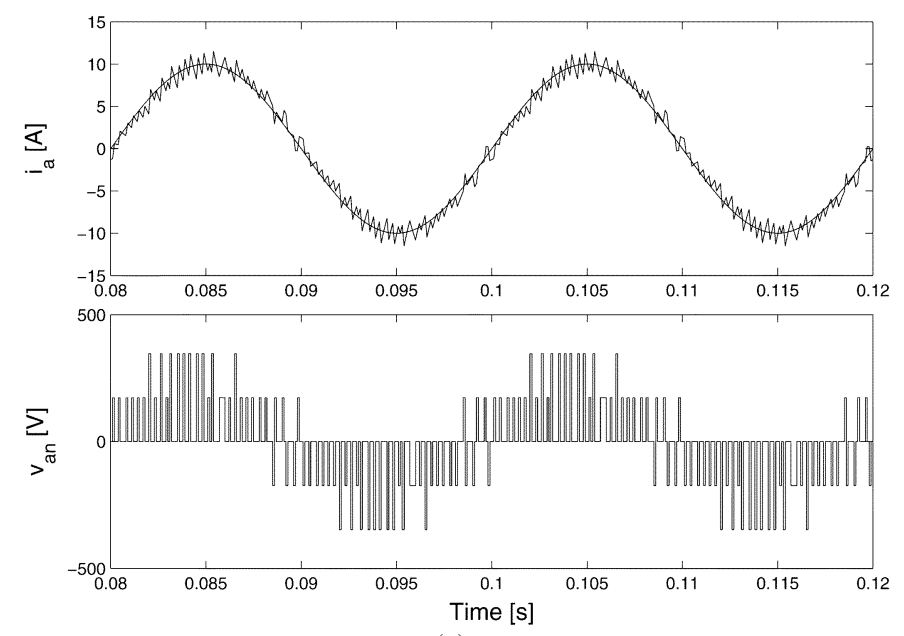

(a)
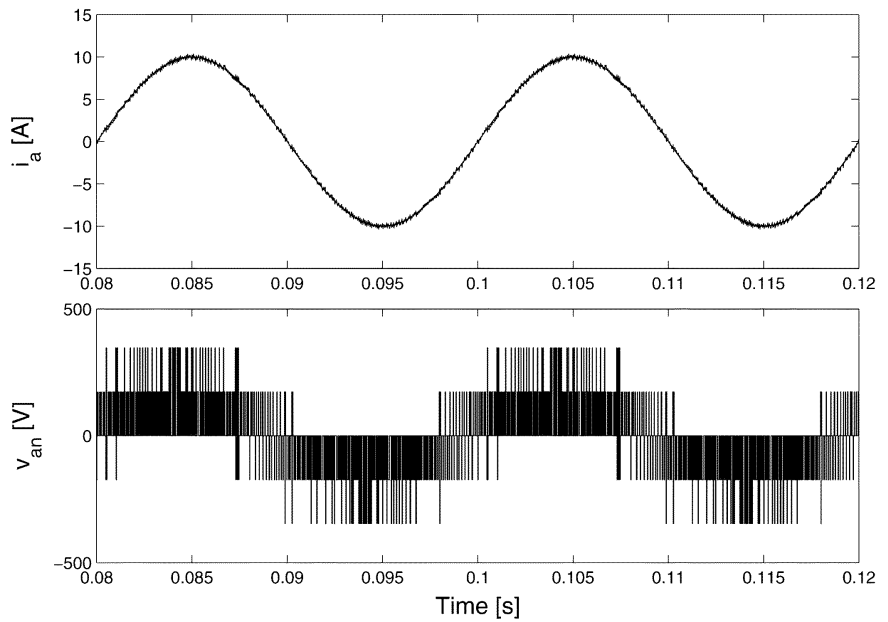

(b)

Fig. 3. Load current and voltage for predictive control without filter: (a) Sampling time $T s=100[\mu \mathrm{s}]$. (b) Sampling time $T s=25[\mu s]$.

Since in (18) filtered variables are evaluated, emphasis can be put on some frequency bands, while others become less relevant. Thus, in this method the voltage vector selection takes into account spectral properties. Indeed, by designing the filter $F$ it is possible to manipulate the spectrum of the load current error. As explained in [19], [20], the error tends to have a spectrum similar to that of the inverse of $F$. It is interesting to note that in (18) not only present but also past values of signals play a role. This stands in stark contrast to (14).

The choice of $F$ determines the spectrum of the load currents. For example, if a concentrated switching frequency spectrum is desired, then (since the obtained spectrum is similar to the one of the inverse of the filter) $F$ should be chosen as a narrow band-stop filter. This situation can be verified by simulation and experimental results as shown in the following sections.

\section{Simulation Results}

The predictive control strategy without and with filtering is simulated in order to evaluate the effect of introducing frequency weighting in the control scheme. The control strategies focus on the control of a three-phase inverter with an active RL load $\left(V_{d c}=520 \mathrm{~V}, R=10 \Omega, L=10 \mathrm{mH}, e=20 V_{\text {peak }}\right)$. 

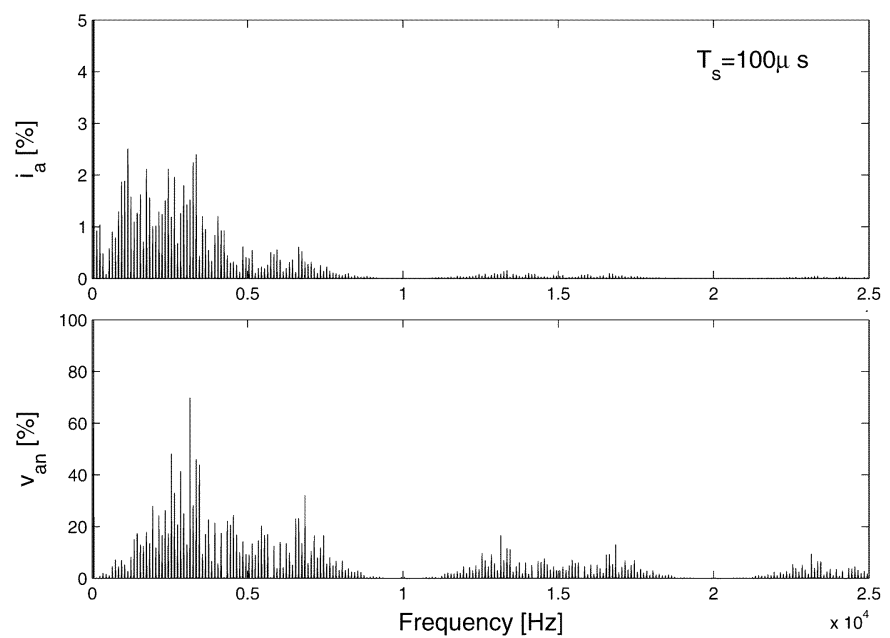

(a)
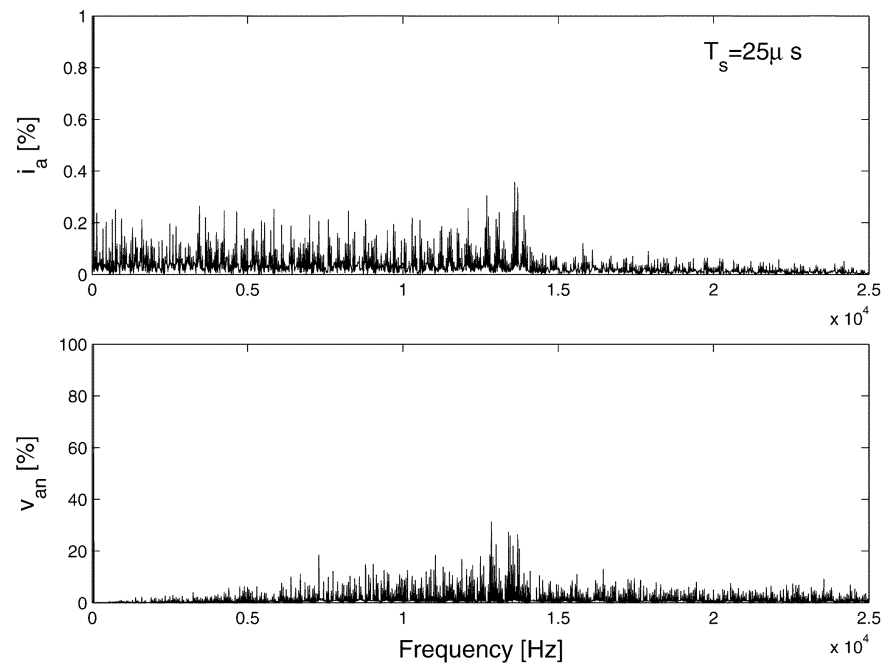

(b)

Fig. 4. Load current and voltage spectrum for predictive control without filter: (a) Sampling time $T s=100[\mu \mathrm{s}]$. (b) Sampling time $T s=25[\mu \mathrm{s}]$.

Typical current and voltage waveforms obtained with the predictive control strategy without using a filter are shown in Fig. 3(a) and (b), with a sampling time of $T_{s}=100 \mu \mathrm{s}$ and $T_{s}=25 \mu \mathrm{s}$, respectively. It is observed that the sampling time has a significant impact on the ripple of the current and the switching frequency of the converter.

The spectrum of the load current and load voltage for the predictive control without filter is shown in Fig. 4 for a sampling time of $T_{s}=100 \mu \mathrm{s}$ and $T_{s}=25 \mu \mathrm{s}$. Although the switching frequency is limited to half the sampling frequency, in both cases the spectrum is spread over a range that depends on the sampling time.

In order to obtain a spectrum which is prescribed, and independent of the sampling frequency, one can employ the frequency weighted predictive control strategy proposed in Section III-B. A near fixed switching frequency, which is comparable to a spectrum that is concentrated around a single frequency, can be obtained by choosing $F$ as the stop-band filter centered around $2 \mathrm{kHz}$ shown in Fig. 5 .

Use of the filter from Fig. 5 in the proposed control strategy with $T_{s}=25 \mu \mathrm{s}$, gives the load voltage spectrum shown at
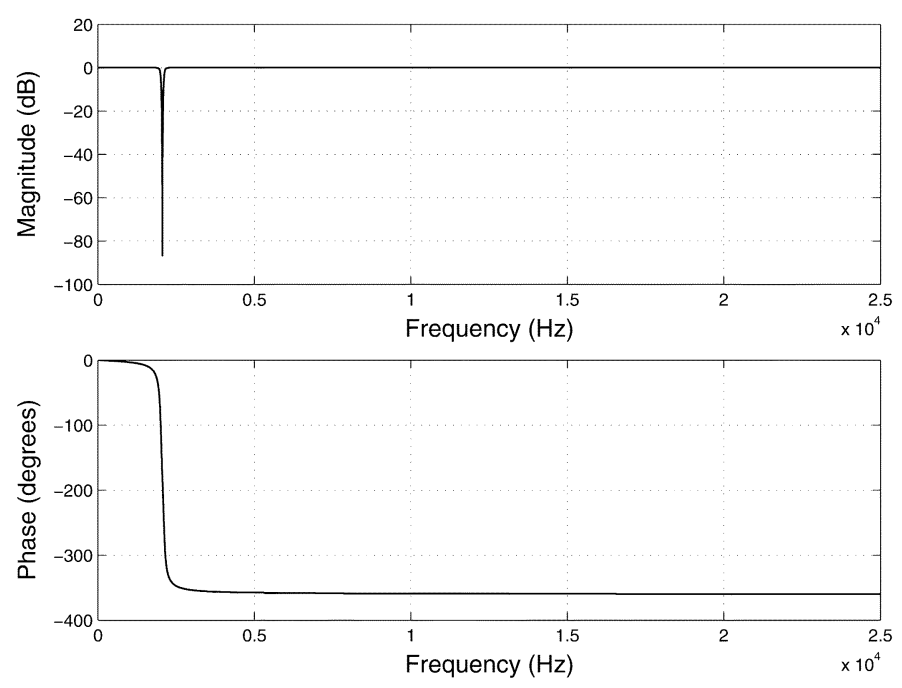

Fig. 5. $F$ band-stop filter centered at $2 \mathrm{kHz}$.
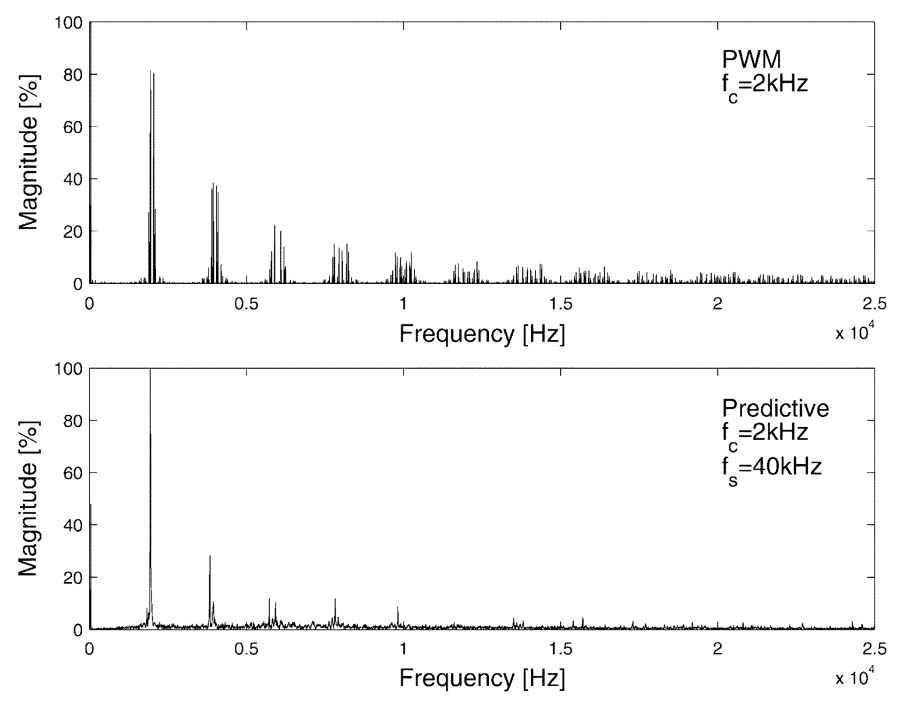

Fig. 6. Load voltage spectrum comparison. Top: PWM. Bottom: Predictive with filter.

the bottom of Fig. 6. At the top of Fig. 6, the load voltage spectrum obtained with PWM current control with a carrier frequency of $f_{c}=2 \mathrm{kHz}$ is shown. It is possible to appreciate that both spectra are very similar, and that the difference with the spectrum obtained using the original predictive control strategy, shown in Fig. 4(b), is very clear.

The effect of evaluating the filtered variables in the cost function (18) can also be noted in the waveforms of the load current and voltage, shown in Fig. 7 and Fig. 8. In contrast with the results shown in Fig. 3(b), here the current presents a clearly defined ripple, similar to the one obtained with PWM control. The limitation of the switching frequency spectrum is observable in the voltage waveform, which presents much less commutations than in the case without the filter, and should be near to a $2 \mathrm{kHz}$ PWM switching pattern.

Results obtained using a band-stop filter $F$ with a center frequency at $4 \mathrm{kHz}$ are shown in Fig. 9. This demonstrates that different shapes of the load current spectrum can be achieved 

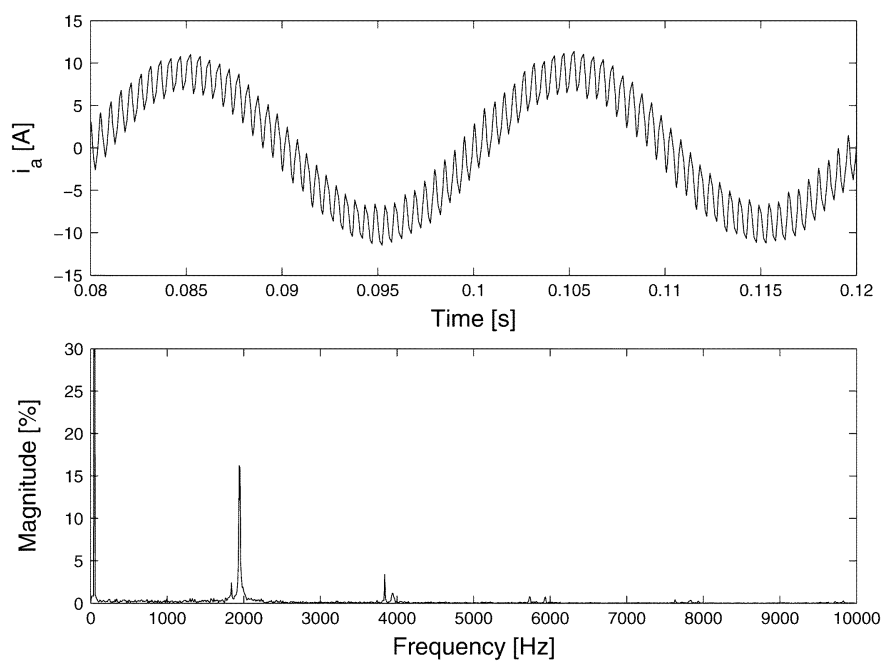

Fig. 7. Load current and its spectrum using a $2 \mathrm{kHz}$ band-stop filter and $T_{s}=$ $25 \mu \mathrm{s}$.
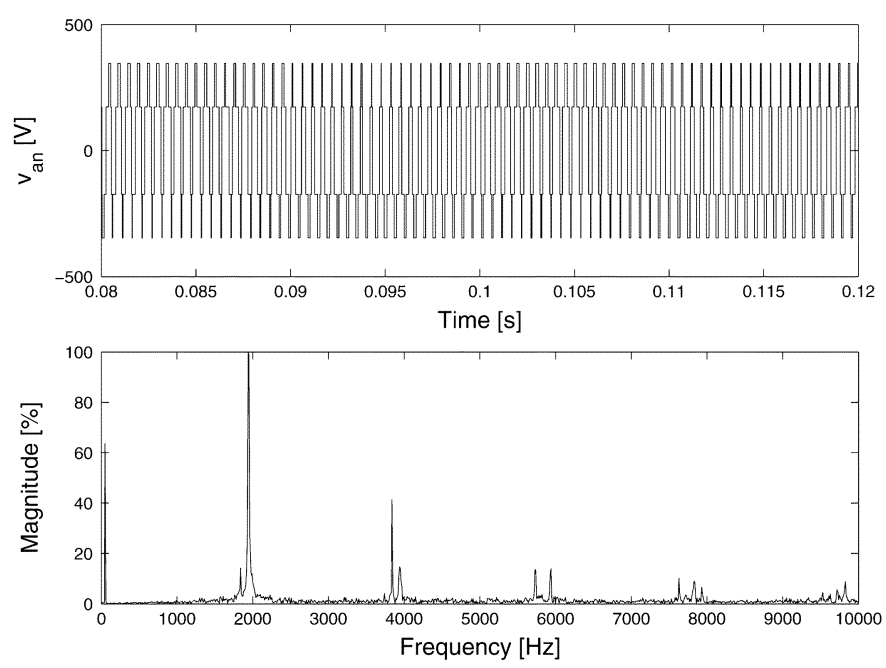

Fig. 8. Load voltage and its spectrum using a $2 \mathrm{kHz}$ band-stop filter and $T_{s}=$ $25 \mu \mathrm{s}$.
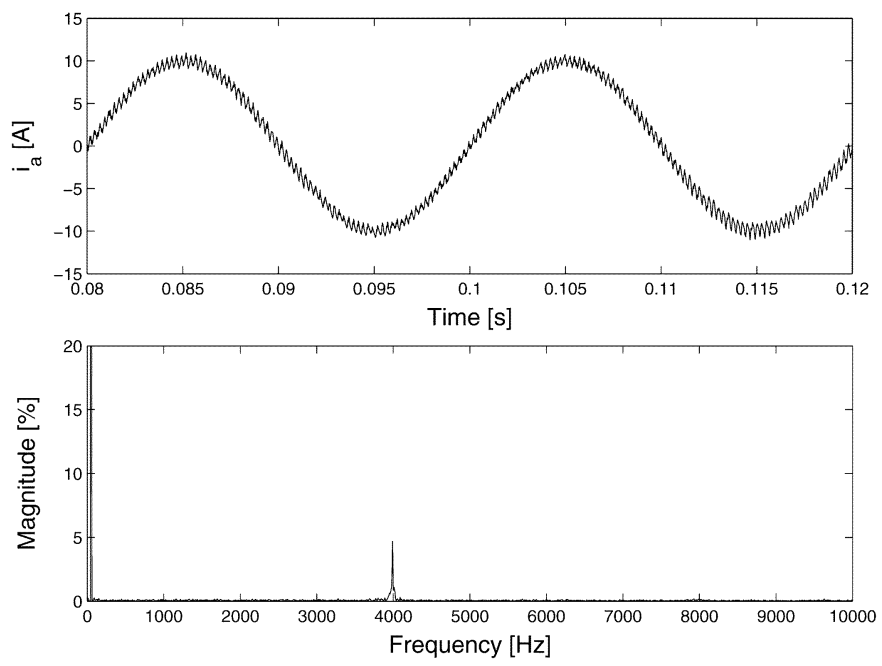

Fig. 9. Load current and spectrum using a $4 \mathrm{kHz}$ band-stop filter and $T_{s}=$ $25 \mu \mathrm{s}$.

independently of the sampling frequency of $40 \mathrm{kHz}$ used for the control.

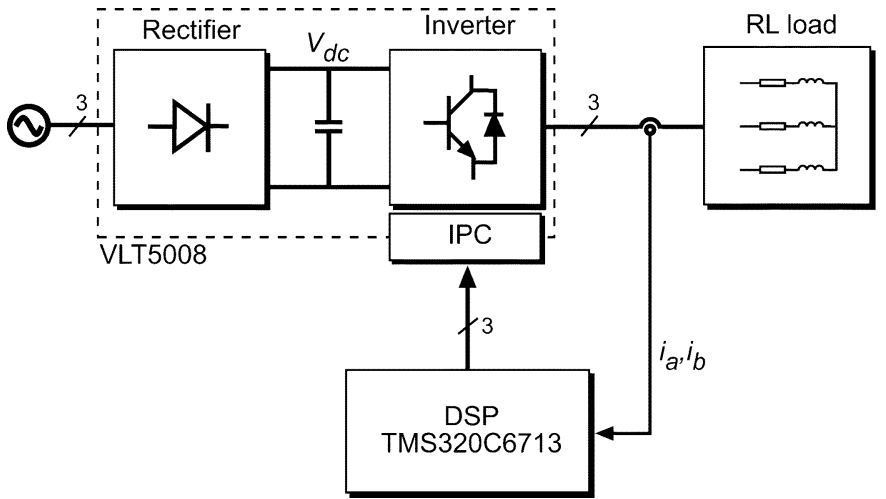

Fig. 10. Experimental system setup overview.
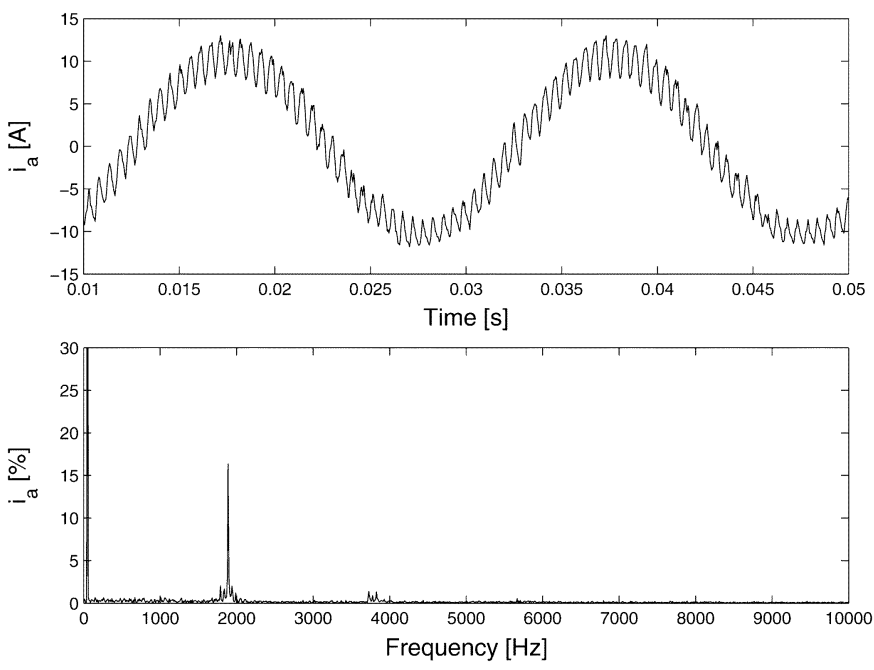

Fig. 11. Experimental result for a $2 \mathrm{kHz}$ band-stop filter and $T_{s}=25 \mu \mathrm{s}$. Load current $i_{a}$ and its spectrum.

\section{EXPERIMENTAL RESULTS}

The proposed frequency weighted predictive current control strategy was tested with the experimental setup described in Fig. 10. A Danfoss VLT5008 $5.5 \mathrm{~kW}$ three-phase inverter with an $\operatorname{RL}$ load $(R=10 \Omega, L=10 \mathrm{mH})$ is used. The dc link is fed by a three-phase diode bridge rectifier $\left(V_{d c}=520 \mathrm{~V}\right)$. The inverter is controlled externally through an interface and protection card (IPC). A TMS320C6713 floating point digital signal processor (DSP) was used for the control. The execution time for the implemented algorithm was about $20 \mu \mathrm{s}$, so the sampling time was set to $T_{s}=25 \mu \mathrm{s}$.

A band-stop filter with the center frequency at $2 \mathrm{kHz}$ was used as the $F$ filter for the load current error (similar to the one shown in Fig. 5). The current in one phase of the load is shown in Fig. 11. The $2 \mathrm{kHz}$ ripple is well defined, and the spectrum of the load current presents a clear peak in $2 \mathrm{kHz}$. This peak can be also seen in the load voltage spectrum shown in Fig. 12.

The load current for a $4 \mathrm{kHz}$ band-stop filter is shown in Fig. 13. The ripple in the current is reduced and the spectrum of the load current appears concentrated in $4 \mathrm{kHz}$. 

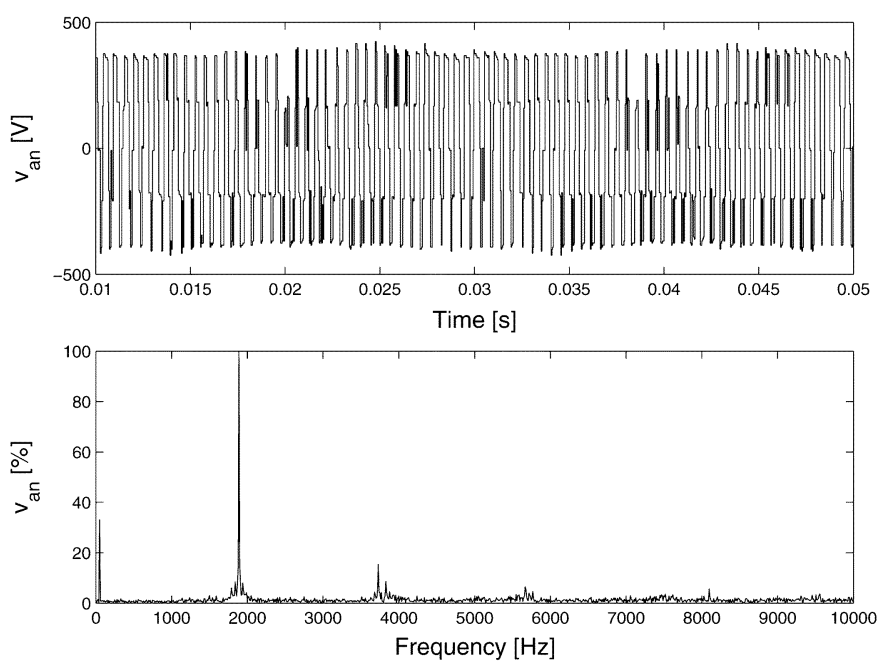

Fig. 12. Experimental result for a $2 \mathrm{kHz}$ band-stop filter and $T_{s}=25 \mu \mathrm{s}$. Load voltage $v_{\text {an }}$ and its spectrum.
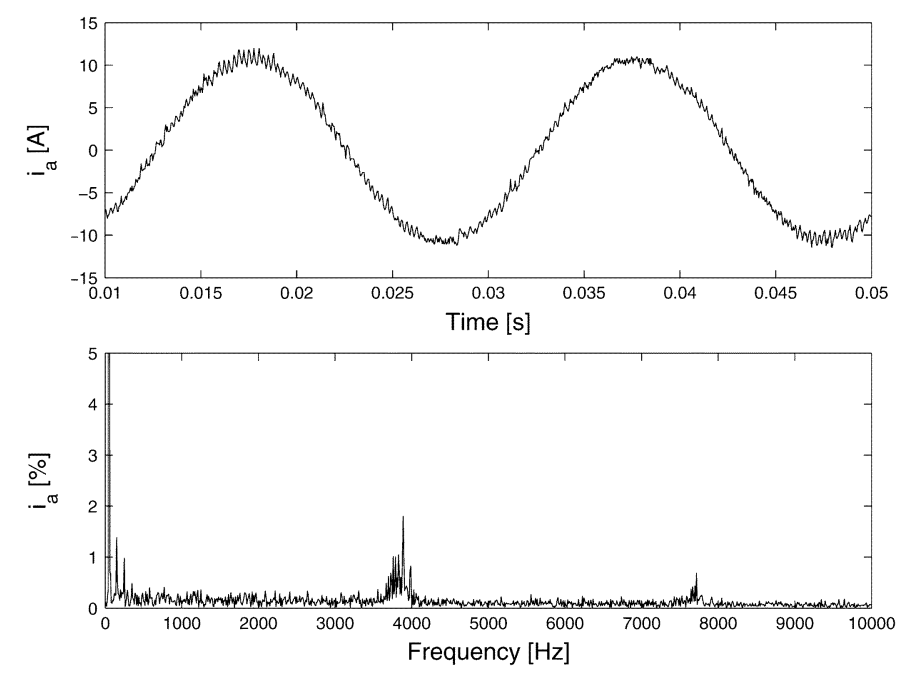

Fig. 13. Experimental result for a $4 \mathrm{kHz}$ band-stop filter and $T_{s}=25 \mu \mathrm{s}$. Load current $i_{a}$ and its spectrum.

\section{CONCLUSION}

We have presented a predictive control strategy which addresses a mayor drawback of previous works on predictive control, namely, that of controlling the current spectrum.

Performing an optimization based on instant values of the currents will generate voltages that have a variable switching frequency, do not follow any pattern and the resulting spectrum is spread over a wide range of frequencies.

In contrast, the inclusion of a filter in the proposed method allows one to evaluate in the cost function the instantaneous variables as well as the frequency information of the controlled variables. The control strategy selects at each sampling time the voltage vector that minimizes the error, and that makes the error spectrum match a certain target.

This contribution is very useful for applications where a fixed frequency is preferred, where the switching losses must be reduced or controlled. The same concept could be used also in certain applications where some frequencies must be avoided to prevent natural modes of the system to be excited.
It has been verified by simulation and in the laboratory that the proposed strategy allows to effectively fix the spectrum within a narrow frequency band. Whilst this does not mean that one has a fixed switching frequency, research is being carried out on how to effectively fix or reduce the switching frequency. Some work on this topic have been presented in [21] for a flying capacitor converter.

Our strategy opens the application of the predictive control based on cost functions to systems where the harmonic content of the variables needs to be controlled.

Predictive control is a very powerful tool that presents a great flexibility to control different kinds of variables. It takes advantage of the discrete nature of power converters and of the microprocessors used for the control and, thus, has become a very attractive alternative for the control of power converters.

\section{REFERENCES}

[1] R. Kennel and A. Linder, "Predictive control of inverter supplied electrical drives," in Proc. IEEE 31st Annu. Power Electron. Spec. Conf., 2000, vol. 2, pp. 761-766.

[2] L. Malesani, P. Mattavelli, and S. Buso, "Robust dead-beat current control for PWM rectifier and active filters," IEEE Trans. Ind. Appl., vol. 35, no. 3, pp. 613-620, May/Jun. 1999.

[3] H. M. Kojabadi, B. Yu, I. A. Gadoura, L. Chang, and M. Ghribi, “A novel DSP-based current-controlled PWM strategy for single phase grid connected inverters," IEEE Trans. Power Electron., vol. 21, no. 4, pp. 985-993, Jul. 2006.

[4] H. Abu-Rub, J. Guzinski, Z. Krzeminski, and H. A. Toliyat, "Predictive current control of voltage source inverters," IEEE Trans. Ind. Electron., vol. 51, no. 3, pp. 585-593, Jun. 2004.

[5] G. Bode, P. C. Loh, M. J. Newman, and D. G. Holmes, "An improved robust predictive current regulation algorithm," IEEE Trans. Ind. Appl., vol. 41, no. 6, pp. 1720-1733, Nov. 2005.

[6] E. Wu and P. W. Lehn, "Digital current control of a voltage source converter with active damping of LCL resonance," IEEE Trans. Power Electron., vol. 21, no. 5, pp. 1364-1373, Sep. 2006.

[7] P. Mattavelli, G. Spiazzi, and P. Tenti, "Predictive digital control of power factor preregulators with input voltage estimation using disturbance observers," IEEE Trans. Power Electron., vol. 20, no. 1, pp. 140-147, Jan. 2005.

[8] A. Nasiri, "Digital control of three-phase series-parallel uninterruptible power supply systems," IEEE Trans. Power Electron., vol. 22, no. 4, pp. 1116-1127, Jul. 2007.

[9] S. Saggini, W. Stefanutti, E. Tedeschi, and P. Mattavelli, "Digital deadbeat control tuning for dc-dc converters using error correlation," IEEE Trans. Power Electron., vol. 22, no. 4, pp. 1566-1570, Jul. 2007.

[10] W. Zhang, G. Feng, Y.-F. Liu, and B. Wu, "A digital power factor correction (PFC) control strategy optimized for DSP," IEEE Trans. Power Electron., vol. 19, no. 6, pp. 1474-1485, Nov. 2004.

[11] K.-S. Low and H. Zhuang, "Robust model predictive control and observer for direct drive applications," IEEE Trans. Power Electron., vol. 15, no. 6, pp. 1018-1028, Nov. 2000.

[12] A. Linder and R. Kennel, "Model predictive control for electrical drives," in Proc. IEEE 36th Power Electron. Spec. Conf., 2005, pp. 1793-1799.

[13] R. Kennel, A. Linder, and M. Linke, "Generalized predictive control (GPC)-ready for use in drive applications?," in Proc. IEEE 32nd Power Electron. Spec. Conf., 2001, vol. 4, pp. 1839-1844.

[14] J. Rodríguez, J. Pontt, C. Silva, P. Correa, P. Lezana, P. Cortés, and U. Ammann, "Predictive current control of a voltage source inverter," IEEE Trans. Ind. Electron., vol. 54, no. 1, pp. 495-503, Feb. 2007.

[15] S. Muller, U. Ammann, and S. Rees, "New time-discrete modulation scheme for matrix converters," IEEE Trans. Ind. Electron., vol. 52, no. 6, pp. 1607-1615, Dec. 2005.

[16] J. Rodríguez, J. Pontt, C. Silva, P. Cortés, S. Rees, and U. Ammann, "Predictive direct torque control of an induction machine," in Proc. Power Electron. Motion Control Conf., Riga, Latvia, Sep. 2-4, 2004, [CD ROM]

[17] J. Rodríguez, J. Pontt, P. Correa, P. Lezana, and P. Cortés, "Predictive power control of an ac/dc/ac converter," in Proc. 40th Annu. IEEE Ind. Appl. Soc., Hong Kong, Oct. 2-6, 2005, vol. 2, pp. 934-939. 
[18] R. Vargas, P. Cortés, U. Ammann, J. Rodriguez, and J. Pontt, "Predictive control of a three-phase neutral point clamped inverter," IEEE Trans. Ind. Electron., vol. 54, no. 5, pp. 2697-2705, Oct. 2007.

[19] D. E. Quevedo and G. C. Goodwin, "Control of EMI from switch-mode power supplies via multi-step optimization," in Proc. Amer. Control Conf., Boston, MA, June 30-July 2 2004, vol. 1, pp. 390-395.

[20] D. E. Quevedo and G. C. Goodwin, "Multistep optimal analog-to-digital conversion," IEEE Trans. Circuits Syst. I, vol. 52, no. 3, pp. 503-515, Mar. 2005.

[21] E. I. Silva, B. P. McGrath, D. E. Quevedo, and G. C. Goodwin, "Predictive control of a flying capacitor converter," in Proc. Amer. Control Conf., New York, NY, Jul. 2007, pp. 3763-3768.

[22] M. Pacas, P. Correa, and J. Rodriguez, "A predictive torque control for inverter-fed induction machines," IEEE Trans. Ind. Electron., vol. 54, no. 2, pp. 1073-1079, Apr. 2007.

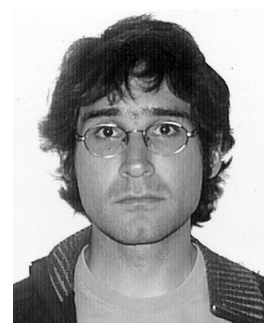

Patricio Cortés (S'05) received the Engineer and M.Sc. degrees in electronic engineering from the Universidad Técnica Federico Santa María (UTFSM), Valparaíso, Chile, in 2004, where he is currently pursuing the $\mathrm{Ph} . \mathrm{D}$. degree.

In 2003, he joined the Electronics Engineering Department, UTFSM, as a Research Assistant. His main research interests are power electronics and adjustable speed drives.

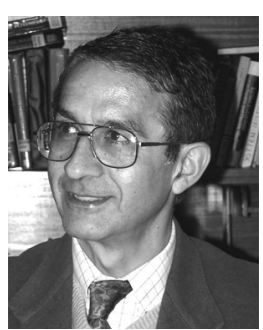

José Rodríguez (M'81-SM'94) received the Engineer and the Dr.-Ing degrees from the University Federico Santa Maria, Chile, in 1977 and the Dr.-Ing. degree from the University of Erlangen, Germany, in 1985, both in electrical engineering.

He has been with the University Federico Santa María, Valparaíso, Chile, since 1977. He is currently a Professor and President at the same university. During his sabbatical leave in 1996 he was responsible for the mining division of the Siemens Corporation in Chile. He has a large consulting experience in the mining industry, especially in the application of large drives like cycloconverter-fed synchronous motors for SAG mills, high power conveyors, controlled drives for shovels and power quality issues. His research interests are mainly in the area of power electronics and electrical drives. In the last years, his main research interests are in multilevel inverters and new converter topologies. He has authored and co-authored more than 130 refereed journal and conference papers and contributed to one chapter in the Power Electronics Handbook (New York: Academic, 2006).

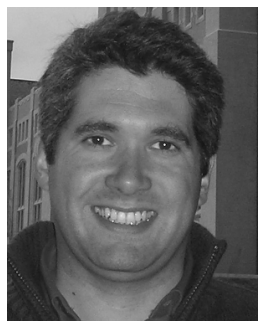

Daniel E. Quevedo received the Ingeniero Civil Electrónico and Magister en Ingeniería Electrónica degrees from the Universidad Técnica Federico Santa María, Valparaíso, Chile, in 2000, and the $\mathrm{Ph} . \mathrm{D}$. degree from The University of Newcastle, NSW, Australia, in 2005.

He is currently with The University of Newcastle, on a Research Academic position. He has lectured at the Universidad Técnica Federico Santa María and The University of Newcastle. His research interests cover several areas of automatic control, signal processing, power electronics, and communications.

Dr. Quevedo received full scholarship from the alumni association during his time at the Universidad Técnica Federico Santa María, several university-wide prizes during graduation, and the IEEE Conference on Decision and Control Best Student Paper Award in 2003.

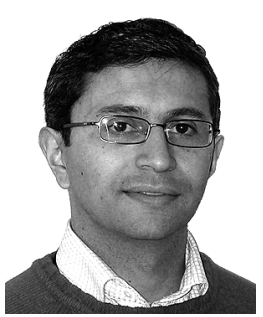

Cesar A. Silva (M'04) was born in Temuco, Chile, in 1972. He received the M.S. degree in civil electronic engineering degree from the University Federico Santa María, Valparaiso, Chile, in 1998 and the $\mathrm{Ph} . \mathrm{D}$. degree from the University of Nottingham, Nottingham, U.K., in 2003. His doctoral thesis was on Sensorless Vector Control of Surface Mounted Permanent Magnet Machines Without Restriction of Zero Frequency.

Since 2003, he has been a Lecturer at the Department of Electronic Engineering, University Federico Santa María, where he teaches basic electric machines theory, power electronics, and ac machine dives. His main research interests are in sensorless vector control of ac machines and control of static converters. He has authored and co-authored more than 10 refereed journal and conference papers on these topics.

Dr. Silva received the Overseas Research Students Awards Scheme (ORSAS) in 1999 . 